
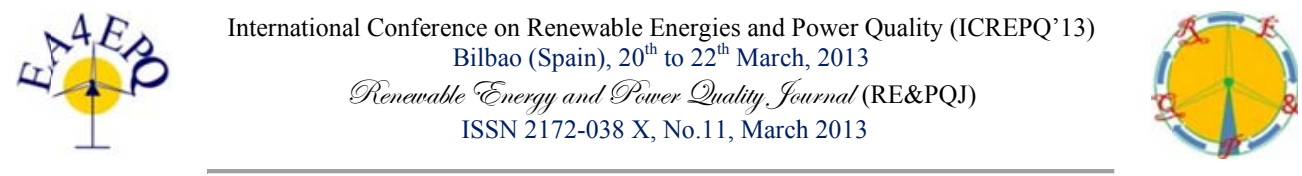

\title{
Engine performance of a single cylinder direct injection diesel engine fuelled with blends of Jatropha Curcas oil and standard diesel fuel
}

\author{
R. Piloto ${ }^{1}$, M. Errasti ${ }^{1}$, N.Ferrer ${ }^{1}$, E. Melo ${ }^{1}$, L. Goyos ${ }^{1}$ and S. Verhelst ${ }^{2}$ \\ ${ }^{1}$ Faculty of Mechanical Engineering, Technical University of Havana \\ Calle 127 s/n, Cujae, Marianao, Habana, 19390, Havana (Cuba) \\ Phone/Fax number: (+537) 765 0976, e-mail: rpiloto@ceter.cujae.edu.cu \\ 2 Department of Flow, Heat and Combustion Mechanics, Faculty of Engineering, Ghent University \\ Sint-Pietersnieuwstraat 41, 9000 Gent (Belgium) \\ Phone, fax, e-mail: sebastian.verhelst@ugent.be
}

\begin{abstract}
Blends of Jatropha Curcas oil and standard diesel fuel were evaluated (without pre-heating). The engine tests for the blends were performed in a Petter single cylinder direct injection diesel engine under steady state conditions at high loads. Engine speeds between 1300-1700 rpm were selected for the engine tests. Torque, power output, specific fuel consumption, in cylinder pressure, ignition delay, rate of heat released and exhaust composition were evaluated. The tested blends between $10-20 \%$ of oil shown lower effective torque and power output joint to a higher specific fuel consumption related to the lower heating value of Jatropha oil compared to diesel fuel. Lower pressure peaks and rates or pressure rises were observed when Jatropha blends are used. A decrease in the rate of heat released and shorter ignition delay were observed for the blends. Decreases in $\mathrm{HC}$ and $\mathrm{CO}$ emissions were observed for blends compared to diesel fuel. Both alternatives assessed shown that the differences observed compared to diesel fuel, can be partially restored with engines regulation. The use of Jatropha oil in order to be a partial or full alternative to the use of diesel fuel for energy production was achieved.
\end{abstract}

\section{Key words}

Jatropha curcas, blends, ignition delay, diesel engine.

\section{Introduction}

The limited amounts of fossil fuels joint to the huge increase in the world demand of them are increasing the efforts for finding better energy solutions, mainly based in the renewable energies [1]-[2].

The use of alternative fuels in Internal Combustion Engines (ICE) can influence the reduction of the use of the traditional fossil fuels in the automotive industry, reduction in the exhaust gas emissions and particulate matter [1]-[3].

The use of biodiesel in a diesel engine brings more advantages than the use of crude oil, mainly due to a higher viscosity found in oils compared to biodiesel (up to
10-20 times higher) [4]. Due to the higher oil viscosity, for its appropriate use in an ICE, a pre-heating system is necessary or blends. Also in some cases, modification of the injection systems can be made [5]. There are also reports of non-saturated fatty acid polymerization during the combustion process when oils are directly used [4]-[6].

For the characterization of a diesel engine using any fuel, some parameters are important as: effective power, specific fuel consumption (SFC), effective torque, exhaust emissions as well as the ignition delay. The last one strongly influences some parameters in the combustion process. It can be evaluated through the behavior of the incylinder pressure (first derivative) [7]-[9].

Jatropha Curcas (physic nut), native of tropical America, has been later introduced into Africa and Asia and is now cultivated worldwide [10]. Jatropha is a genus of approximately 175-200 plants, shrubs and trees, from the family of Euphorbiaceae. It is resistant to drought and produces seeds containing up to $40 \%$ mass of oil. When the seeds are crushed and processed, the resulting oil can be used in a standard diesel engine [11]-[14] when measures are taken to decrease the viscosity: preheating of the oil, blending with diesel fuel or converting the oil to biodiesel using the esterification reaction.

In a comparison between crop efficiencies for biodiesel production, only algae and palm oil yield better results than Jatropha Curcas. While important amounts of biodiesel are nowadays produced from edible sources, a challenge for biodiesel production is to use feedstocks that would not compete with human food. In that direction, Jatropha Curcas has been identified among the most promising non-edible oil-bearing seeds for biodiesel production. Jatropha produces mainly a non-edible oil due to the phorbol esters that are toxic [15], even at very low concentration. 
The purpose of this work is to evaluate the performance of a single cylinder diesel engine fuelled with blends of Jatropha Curcas oil and standard diesel fuel. The comparison of the performance of the Petter engine with two selected blends covers torque, effective power, SFC, ignition delay, rate of heat released (ROHR), $\mathrm{HC}$ and $\mathrm{CO}$ exhaust emissions.

\section{Experimental set-up and procedures}

Blends of Jatropha Curcas oil and standard diesel fuel were prepared as binary systems at $10 \%$ (JC10) and $20 \%$ (JC20). The density of the isolated components and the blends selected for engine tests were evaluated using a picnometer standard of $25 \mathrm{~mL}$. The dynamic viscosity of the components and the blends were evaluated using a RION viscometer VT 03-F.

The engine used was a Petter single cylinder direct injection diesel engine. The main engine characteristics are given in Table I. The experiments were carried out upper stoichiometric ratio $(\lambda>1)$, steady state conditions at high loads and different engine speeds. Engine speeds $(n)$ between 1300-1700 rpm were selected for the engine tests.

Table I. - Characteristics of the Petter engine

\begin{tabular}{|c|c|}
\hline item & value \\
\hline bore & $87.3 \mathrm{~mm}$ \\
\hline stroke & $110 \mathrm{~mm}$ \\
\hline compression ratio & $16.5: 1$ \\
\hline cubic capacity per cylinder & $659 \mathrm{~cm}^{3}$ \\
\hline fuel injection timing & $\begin{array}{c}24^{\circ} \text { before Top Dead Center } \\
\text { (TDC) } \\
\text { (up to 1650 rpm) }\end{array}$ \\
\cline { 2 - 2 } & $\begin{array}{c}28^{\circ} \text { before TDC (1651-2000 } \\
\text { rpm) }\end{array}$ \\
\hline type of cooling & water-cooled \\
\hline
\end{tabular}

The schematic diagram of the experimental setup used for the engine tests is shown in Fig.1. Two Kistler pressure sensors were installed for the in-cylinder pressure measurements: a water-cooled absolute pressure sensor type $6067 \mathrm{C}$ and a piezoresistive absolute pressure sensor type 4075A. A Kistler signal conditioning platform with a charge amplifier type 5064 and a piezoresistive amplifier type 4665 were also installed. A data acquisition card from Addi-Data was used for the registering of the pressure measurements. A crank angle encoder Kistler type $2613 \mathrm{~B}$ that is an optical encoder system to provide the correlation between pressure measurement signal and crank angles $\left({ }^{\circ} \mathrm{Ca}\right)$ position with a resolution of $1{ }^{\circ} \mathrm{Ca}$ was used. The equipment used for measuring the exhaust $\mathrm{HC}$ and $\mathrm{CO}$ emissions was an emissions analyser Testo 350 with a resolution of $10 \mathrm{ppm}$. The measurement of the exhaust gases was developed at the end of the pipe line and outside the installation located six meters from the engine. All the experiments were developed and analysed three times.

\section{Results and Discussion}

The results of density and viscosity measurements are shown in Table II.

Table II. - Results of viscosity and density measurements

\begin{tabular}{|c|c|c|}
\hline \multirow{2}{*}{ fuel } & \multicolumn{2}{|c|}{ physical properties } \\
\cline { 2 - 3 } & density $\left(\mathrm{g} / \mathrm{cm}^{3}\right)$ & viscosity $(\mathrm{mPa} \cdot \mathrm{s})$ \\
\hline diesel fuel & 0.893 & 3.4 \\
\hline JC10 & 0.902 & 5.0 \\
\hline JC20 & 0.911 & 7.2 \\
\hline JC & 0.983 & 30.5 \\
\hline
\end{tabular}

As is observed in Table II, the dynamic viscosity of JC10 is $1.6 \mathrm{mPa} \cdot \mathrm{s}$ higher than the value found for the reference fuel while the difference for JC20 was $3.8 \mathrm{mPa} \cdot \mathrm{s}$ higher. The density measurements did not evidence significant differences among fuels and according to these results they are adequate for their use in the engine.

Concerning the engine performance, the results of the effective torque (Te) comparison between diesel fuel and the blends are shown in Fig.2. A decrease in the effective torque when the percent of Jatropha is increased was observed for every experimental test. Also slight decreases in the effective power output were observed when the Jatropha percent is increased. Both behaviors are associated to the lower heating value of the oil compared to diesel fuel. The general behavior observed in Fig. 2 for all the fuels tested is associated to the volumetric efficiency.

The results of the specific fuel consumption are shown in Fig.3. When Jatropha is used, increases in the brake SFC are registered at any experimental condition is observed, mainly due to the lower heating value of the oil and the blends. Same behaviors concerning these engine performance parameters are reported [16].

The evaluation and comparison of the ignition delay results at different engine speeds were based in the first derivative of the in-cylinder pressure. A comparison between the rate or pressure rise diagram for reference diesel fuel and JC10 at $1700 \mathrm{rpm}$ is shown in Fig. 4. The dash line represents the reference diesel fuel and the continuous line the JC10. The results shown shorter ignition delay (in crank angles) compared to diesel fuel in agreement with reports [7],[16]. This can be related to the higher cetane number of the oil compared to diesel fuel and therefore that also affects blends tested. It is well known that higher cetane number shortening the ignition delay [8],[17]-[20].

The results above exposed shown that the use of blends of Jatropha Curcas oil between 10-20\% involves some variations in the main engine performance parameters, increasing the fuel consumption, decreasing effective torque, power output and shortening the ignition delay. According to these results, their use for energy production in ICE is possible, but for a better use of the energy, a regulation of the engine is suggested in order to reach closer ignition delay intervals compared to diesel fuel. 


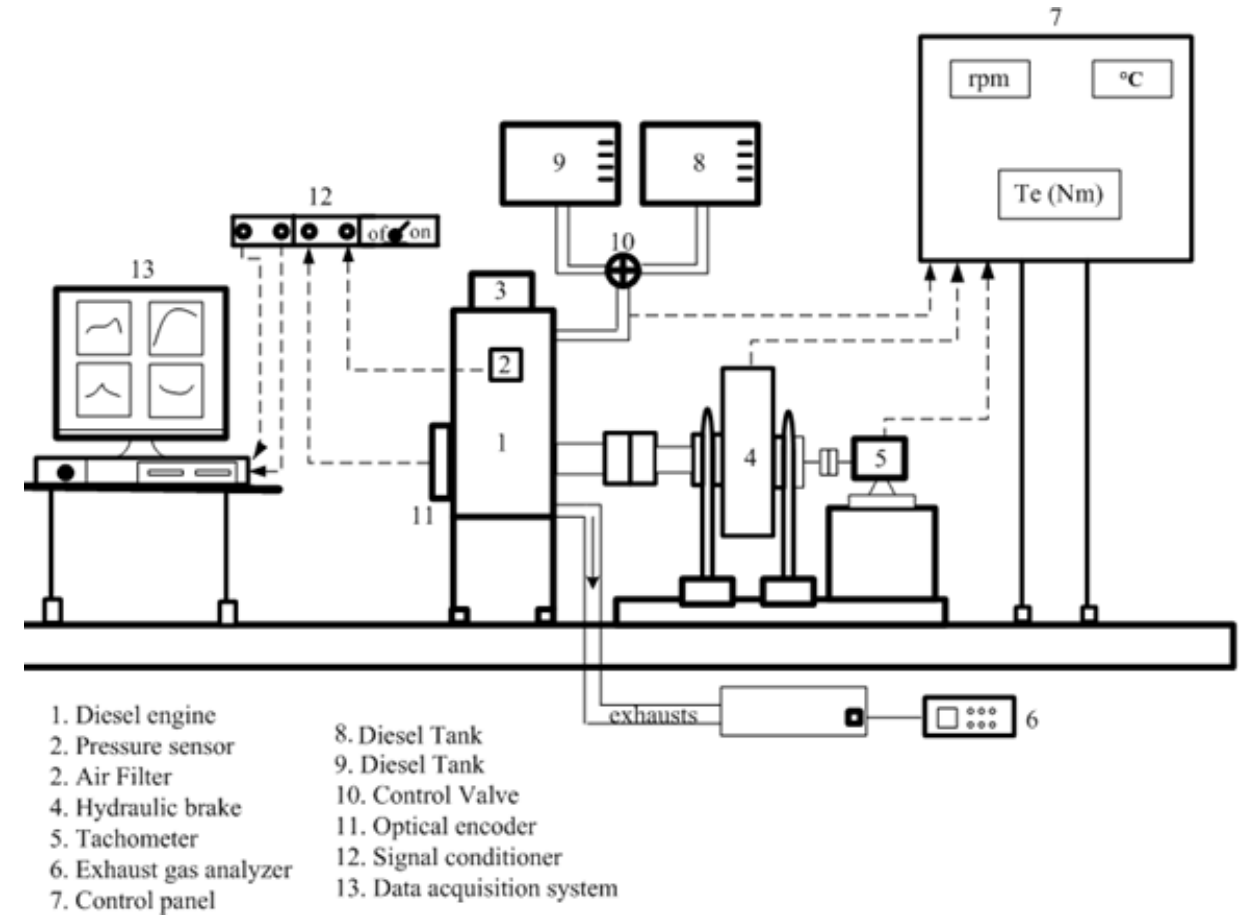

Fig. 1. Schematic diagram of the engine bench tests setup

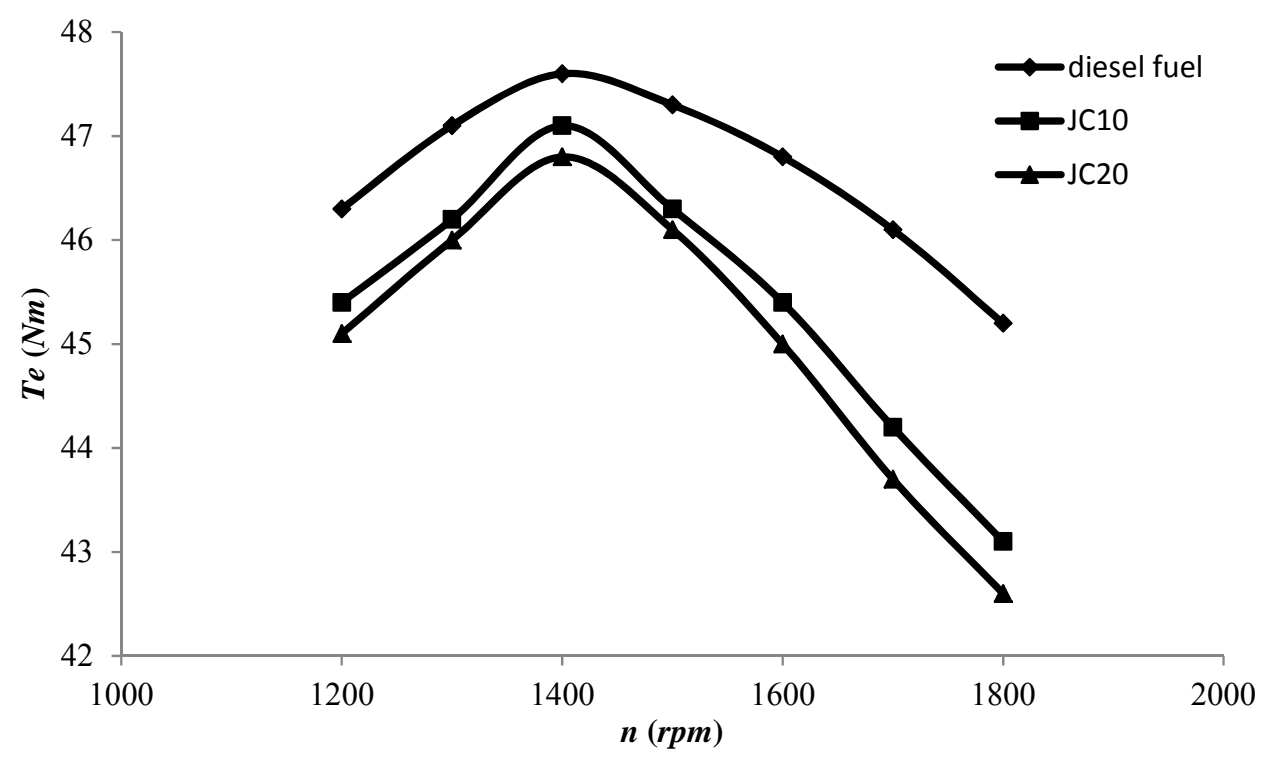

Fig. 2. Effective torque for the engine tests

The evaluation of the ignition delay was also based in the Rate of Heat Released diagrams in order to compare with the obtained under the above described experimental method based on the in-cylinder pressure profile. The results from both methods were in the same order and similar uncertainties in the determinations were found. There are other criteria for the evaluation of the start of combustion and ignition delay [21], but both criteria selected are two of the most sensitive and widely used.
Similar or slightly lower pressure peaks were observed when blended Jatropha Curcas is used. A decrease in the rate of heat released was also observed for the oil and its blends. Concerning the exhausts, decreases in $\mathrm{HC}$ and $\mathrm{CO}$ emissions were observed for Jatropha oil or its blends compared to diesel fuel. The decreases found down to 5 $\%$ compared to diesel fuel. These results can be due to better combustion efficiency due to the higher cetane number of the blends compared to diesel fuel. Therefore, even when the engines performance analysis brought no better results according to the biofuel characteristics, its 
use bring two important advantages: reduction of some pollutant species and an alternative fuel to cover in part or totally the use of conventional diesel fuel to produce energy in internal combustion diesel engines.

The use of biofuels can to reduce exhaust emissions, specially lower soot is generated during the combustion process due to the oxygen contained in the fuel. However, the higher viscosity, density, and surface tension levels found may result in poor atomization characteristics, leading to a lower combustion pressure and rate of heat release in an internal combustion engine [22]. In this research, this behavior was not clearly observed and will be checked in further works. It can be associated to the use of diesel fuel and blends of Jatropha curcas at low percents of the oil in the blend.

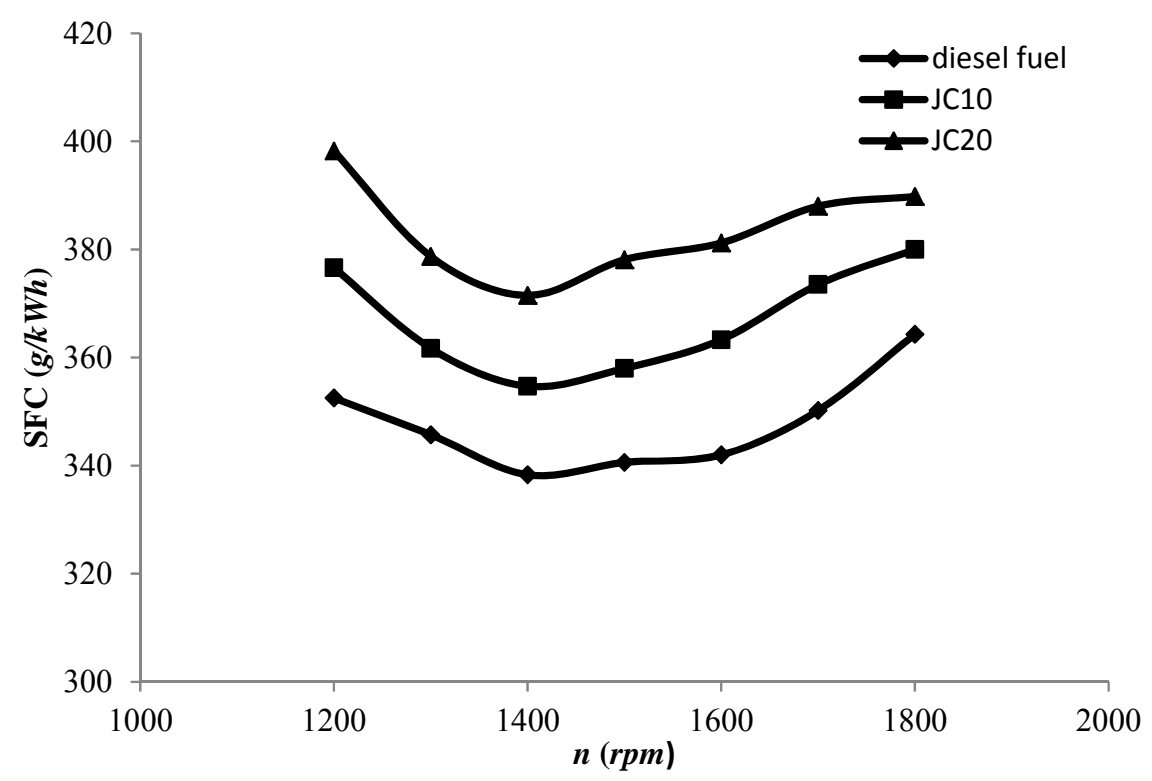

Fig. 3. Specific fuel consumption for the fuels tested

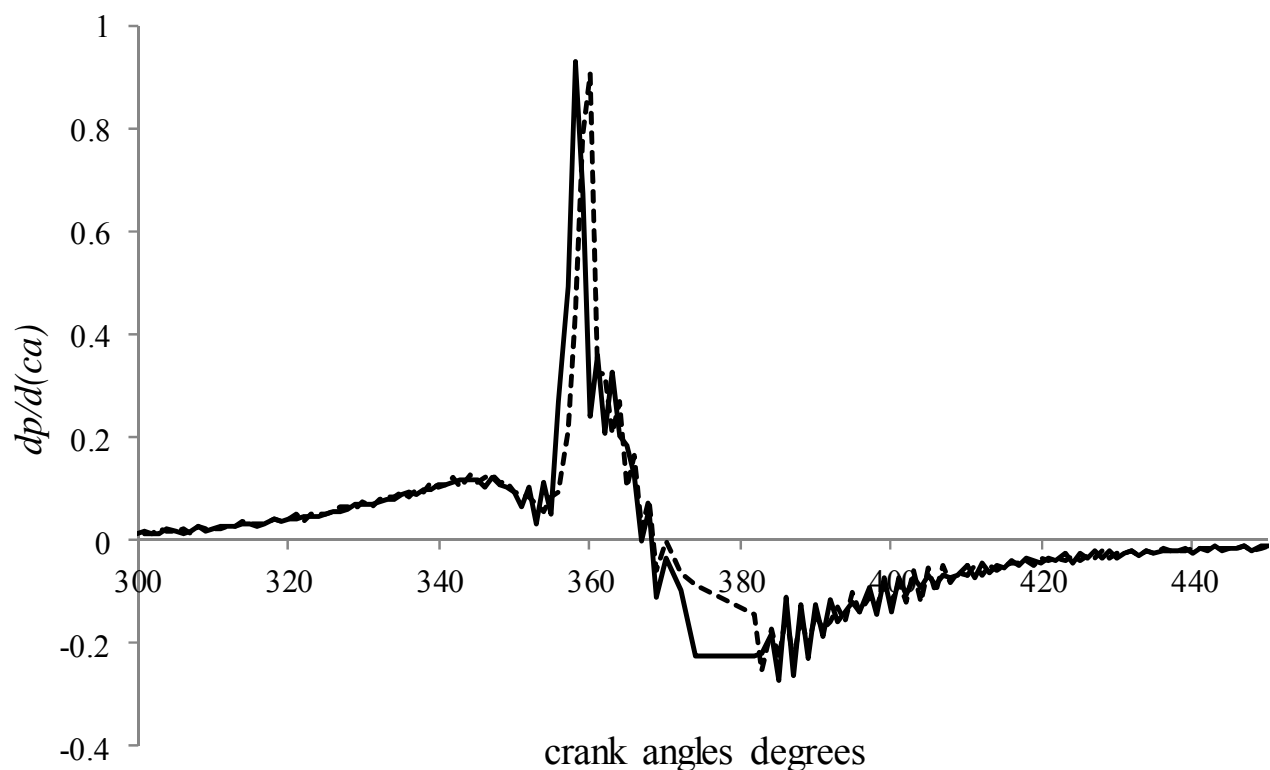

Fig. 4. Plot of $d P / d(c a)$ for the ignition delay estimation at $1700 \mathrm{rpm}$

The results obtained in this work are a first step in the introduction of the use of Jatropha Curcas derived biofuels for their use in internal combustion engines in order to solve problems related to the agricultural transport of local farmers in Cuba, a country that depends on the fossil fuels for the automotive engines. In further 
works, testing of pure pre-heated Jatropha oil and the derived methyl esters (biodiesel) will be evaluated. Even when in this work was only the blend of Jatropha oil and diesel fuel evaluated, using a pre-heating system is possible to use pure oil for energy production in ICE. The use does not need to be processed and only a filtering process is necessary. Also some by-products of Jatropha

\section{Conclusions}

The tested blends between $10-20 \%$ of Jatropha Curcas oil shown lower effective torque and power output joint to a higher specific fuel consumption related to the lower heating value of the oil compared to diesel fuel. Lower pressure peaks and rates or pressure rises were observed when Jatropha Curcas is used. A decrease in the rate of heat released and shorter ignition delay were observed for the blends compared to diesel fuel. Also decreases in HC and $\mathrm{CO}$ emissions were observed for the blends. Both alternatives assessed shown that the differences observed concerning to the engines performance can be partially restored with engines regulation. The use of Jatropha oil in order to be a partial or full alternative to the use of diesel fuel for energy production in a single cylinder diesel engine was preliminarily achieved.

\section{Acknowledgement}

The authors wish to express their thanks to the Flemish Interuniversity Council's (VLIR) University Development Cooperation, funding an Own Initiatives Program, with whose support much of this work was performed under a project entitled "Knowledge cell on biofuels (from nonedible crops and waste products) for use in internal combustion engines".

\section{References}

[1] A. Demirbas, Biodiesel. A realistic fuel alternative for diesel engines, Springer-Verlag, London (2008).

[2] A.K. Agarwal, "Biofuels (alcohols and biodiesel) applications as fuels for Internal Combustion Engines", in Progress in Energy and Combustion Science 2007, Vol. 33, pp. 233-271.

[3] C. Carraretto, A. Macor, A. Mirandola, A. Stoppato and S. Tonon, "Biodiesel as alternative fuel: Experimental analysis and energetic evaluations", in Energy 2004. Vol. 29, pp. 2195-2111.

[4] S. Bari, T.H. Lim and C.W. Yu, "Effects of preheating of crude palm oil (CPO) on injection system, performance and emission of a diesel engine" in Renewable Energy 2002, Vol. 27, pp. 339-351.

[5] A.S. Ramadhas, C. Muraleedharan and S. Jayaraj, "Performance and emission evaluation of a diesel engine fueled with methyl esters of rubber seed oil" in Renewable Energy 2005, Vol. 30, pp. 1789-1800.

[6] M.S. Graboski, J.D. Ross and R.L. McCormick, "Transient emissions from no. 2 diesel and biodiesel blends in a DDC series 60 engine" in SAE paper 1996, 961166.

[7] R. Piloto, Determination of biodiesel influence on the performance of diesel engines, Department of Flow, Heat \& Combustion Mechanics, Ghent University, Ghent (2010). ISBN 978-90-8578-362-6.

[8] R. Piloto, R. Sierens and S. Verhelst, "Ignition delay in a palm oil and rapeseed oil biodiesel fuelled engine and predictive correlations for the ignition delay period" in Fuel 2011, Vol. 90, pp 766-772. can be used for energy production. The shell can be transformed into biogas; the press cake is used as fertilizer and after drying can be used as a solid fuel.

[9] D.N. Assanis, Z.S. Filipi and S.B. Fiveland, "A predictive ignition delay correlation under steady-state and transient operation of a direct injection diesel engine" in Transactions of the ASME 203, Vol. 145, pp. 450-457.

[10] S. Ganesh Ram, K.T. Parthiban, R. Senthil Kumar, V. Thiruvengadam and M. Paramathma, "Genetic diversity among Jatropha species as revealed by RAPD markers" in Genet Resour Crop Evol. 2008, Vol. 55, pp. 803-809.

[11] M.M. Azam, A. Waris and N.M. Nahar, "Prospects and potential of FAME of some non-traditional seed oils for use as biodiesel in India" in Biomass \& Bioenergy 2005, Vol. 29, pp. 293-302.

[12] K. Pramanik, "Properties and use of Jatropha curcas oil and diesel fuel blends in compression ignition engine" in Renewable Energy 2003, Vol. 28, pp. 239-248.

[13] P.K. Sahoo, L.M. Das, M.K.G. Babu, P. Arora, V.P. Singh and N.R. Kumar, "Comparative evaluation of performance and emission characteristics of jatropha, karanja and polanga based biodiesel as fuel in a tractor engine" in Fuel 2009, Vol. 88, pp. 1698-1707.

[14] P.K. Sahoo and L.M. Das, "Combustion analysis of Jatropha, Karanja and Polanga based biodiesel as fuel in a diesel engine" in Fuel 2009, Vol. 88, pp. 994-999.

[15] J. Martinez-Herrera, P. Siddhuraju, G. Francis, G. DavilaOrtız and K. Becker, "Chemical composition, toxic/antimetabolic constituents, and effects of different treatments on their levels, in four provenances of Jatropha curcas L. from Mexico" in Food Chemistry 2006, Vol. 96, pp. 80-89.

[16] A.S. Ramadhas, S. Jayaraj and C. Muraleedharan, "Use of vegetable oils as IC engine fuels-a review", in Renewable Energy 2004, Vol. 29, pp. 727-742.

[17] A. Gopinath, S. Puhan and G. Nagarajan, "Relating the cetane number of biodiesel fuels to their fatty acid composition: a critical study" in Journal of Automobile Engineering 2009, Vol. 223, pp. 565-583.

[18] Y. Icingur and D. Altiparmak, "Effect of fuel cetane number and injection pressure on a DI Diesel engine performance and emissions" in Energy Conversion \& Management 2003, Vol. 44, pp. 389-397.

[19] G. Knothe, "Dependence of biodiesel fuel properties on the structure of fatty acid alkyl esters" in Fuel Processing Technology 2005, Vol. 86, pp. 1059-1070.

[20] G. Knothe, "Cetane numbers of branched and straightchain fatty esters determined in an ignition quality tester" in Fuel 2003, Vol. 82, pp. 971-975.

[21] D.N. Assanis, S.Z. Filipi, S.B. Fiveland and M. Syrimis, "A predictive ignition delay correlation under steady-state and transient operation of a direct injection diesel engine", in Fuel 2003, Vol.125, pp. 450-457.

[22] H.K. Suh, S.W. Park and C.S. Lee, "Effect of grouped-hole nozzle geometry on the improvement of biodiesel fuel atomization characteristics in a compresion ignition engine", in Proceedings of the Institution of Mechanical Engineers, Part D: Journal of Automobile Engineering 2009, Vol. 223, pp.15871600 . 